\title{
Neoadjuvant chemotherapy for brain tumors in infants and young children
}

\author{
Junya Iwama, MD, ${ }^{1}$ Hideki Ogiwara, MD, PhD, ${ }^{1}$ Chikako Kiyotani, MD, ${ }^{2}$ Keita Terashima, MD, PhD, ${ }^{2}$ \\ Kentaro Matsuoka, MD, PhD, ${ }^{3}$ Hideto Iwafuchi, MD, ${ }^{3}$ and Nobuhito Morota, MD'
}

Divisions of ${ }^{1}$ Neurosurgery, ${ }^{2}$ Neuro-Oncology, and ${ }^{3}$ Pathology, National Center for Child Health and Development, Tokyo, Japan

\begin{abstract}
OBJECT Because of their large size and high vascularity, complete removal of brain tumors in infants and young children is often difficult. In most cases the degree of resection is associated with prognosis. Neoadjuvant chemotherapy may facilitate resection by reducing the vascularity of the tumor. The authors evaluated the effectiveness of neoadjuvant chemotherapy in the management of these tumors.
\end{abstract}

METHODS The authors performed a retrospective review of infants and young children who underwent tumor removal after neoadjuvant chemotherapy.

RESULTS Nine consecutive patients underwent resection after neoadjuvant chemotherapy during the period February 2004 to December 2012. The mean age at diagnosis was 18 months (range 2-50 months). The average largest tumor diameter was $71 \mathrm{~mm}$ (range 30-130 mm) at initial surgery. Five patients underwent partial resection, and 4 underwent biopsy as the initial surgery. The histopathological diagnoses were ependymoma in 2 patients, anaplastic ependymoma in 1, primitive neuroectodermal tumor (PNET) in 2, choroid plexus carcinoma in 1, atypical teratoid/rhabdoid tumor (AT/ RT) in 1, glioblastoma in 1, and embryonal tumor with abundant neuropil and true rosettes in 1. After 2-4 courses of multiagent chemotherapy (mainly with vincristine, cyclophosphamide, etoposide, and cisplatin), the second-look surgery was performed. In 1 patient with a PNET, intratumoral hemorrhage was observed after 2 courses of chemotherapy. The mean interval between the initial and the second-look surgery was 3 months. The tumor volume was reduced to varying degrees in 5 patients (56\%) after chemotherapy. Intraoperatively, the vascularity of the tumor was considerably reduced, and the tumor was more circumscribed in all cases. Gross-total resection was achieved in 8 patients (89\%) and neartotal resection in $1(11 \%)$. Histopathological examination demonstrated fibrotic tissue circumscribing the tumor in 6 of 9 cases $(67 \%)$. The average blood loss was $20 \%$ of the estimated blood volume, and 3 patients $(33 \%)$ required a blood transfusion. There was no surgical mortality. One patient had transient dysphasia postoperatively. The mean follow-up period was 28 months. At the last follow-up, 2 patients (22\%) had died (1 died of tumor progression and 1 of sepsis), and 4 patients (44\%) had no tumor recurrence.

CONCLUSIONS Neoadjuvant chemotherapy for brain tumors in infants and young children was effective in reduction of tumor vascularity and clarification of the tumor-brain interface, which significantly facilitated maximal tumor resection. http://thejns.org/doi/abs/10.3171/2014.11.PEDS14334

KEY WORDS neoadjuvant chemotherapy; infantile brain tumors; second-look surgery; oncology

$\mathrm{B}$ RAIN tumors in infants and young children are frequently large and highly vascular. While more extensive resection has been demonstrated to correlate with improved outcomes in most brain tumors in infants and young children, complete resection is often challenging due to the risks of neurological complications and excessive blood loss. ${ }^{2,4,6}$ In such cases, neoadjuvant chemotherapy may reduce the size and/or the vascularity of the tumor, facilitate maximal tumor resection, and contribute to improving outcomes. ${ }^{5,9}$ We retrospectively analyzed the intraoperative blood loss, extent of resection, neurological complications, and outcomes after secondlook surgery following neoadjuvant chemotherapy in 9 patients with brain tumors.

ABBREVIATIONS AT/RT = atypical teratoid/rhabdoid tumor; CPC = choroid plexus carcinoma; ETANTR = embryonal tumor with abundant neuropil and true rosettes; GTR = gross-total resection; ICE = ifosfamide, carboplatin, and etoposide; NTR = near-total resection; PNET = primitive neuroectodermal tumor. SUBMITTED June 27, 2014. ACCEPTED November 12, 2014.

INCLUDE WHEN CITING Published online February 27, 2015; DOI: 10.3171/2014.11.PEDS14334.

DISCLOSURE The authors report no conflict of interest concerning the materials or methods used in this study or the findings specified in this paper. 


\section{Methods}

We performed a retrospective study of 9 infants and young children who underwent a biopsy or partial resection of brain tumors followed by induction chemotherapy and second-look surgery at the National Center for Child Health and Development, Tokyo, during the period February 2004 to December 2012. The study was approved by the institutional review board of the National Center for Child Health and Development. Magnetic resonance imaging was performed in all patients before and after an initial surgery and after each course of chemotherapy to evaluate the response to chemotherapy and determine the timing of second-look surgery. All patients received several courses of chemotherapy comprising vincristine, cyclophosphamide, etoposide, and cisplatin, or ifosfamide, carboplatin, and etoposide (ICE). The choice of chemotherapy was selected mainly by the individual neurooncologist's preference. Second-look surgery was performed when no further reduction in tumor size or a regrowth of tumor was demonstrated, or when a chemotherapy-related complication such as intratumoral hemorrhage was observed. We administered at least 2 courses of the chemotherapy even when the first course of chemotherapy did not reduce the tumor size. Extent of resection was defined from MR images obtained after the second-look surgery and was categorized as gross-total resection (GTR; no radiologically apparent residual tumor), near-total resection (NTR; a reduction of $>95 \%$ in tumor volume), subtotal resection (a reduction of 50\%-95\% in tumor volume), or partial resection (reduction of $<50 \%$ in tumor volume). For the statistical analysis, the outcomes for the 2 groups were compared using Fisher's exact test due to the small sample size. A value of $p<0.05$ was considered significant.

\section{Results \\ Patient Characteristics}

Nine consecutive patients underwent resection after neoadjuvant chemotherapy during the period February 2004 to December 2012. Patient characteristics are shown in Table 1. The mean age at diagnosis was 18 months (range 2-50 months). There were 6 supratentorial tumors and 3 infratentorial tumors. The average largest diameter of the tumor at initial surgery was $71 \mathrm{~mm}$ (range 30-130 $\mathrm{mm}$ ). One patient with choroid plexus carcinoma (CPC) had evidence of metastatic disease at diagnosis.

\section{Initial Surgery}

Five patients underwent partial resection, and 4 underwent biopsy as initial surgery. We did not progress to further resection because significant or life-threatening intraoperative blood loss was expected due to high vascularity and large tumor size. We confined the surgery to the biopsy when the tumor was extremely vascular. The histopathological diagnoses were ependymoma in 2 patients, anaplastic ependymoma in 1, primitive neuroectodermal tumor (PNET) in 2, CPC in 1, atypical teratoid/rhabdoid tumor (AT/RT) in 1, glioblastoma in 1, and embryonal tumor with abundant neuropil and true rosettes (ETANTR) in 1 .

\section{Neoadjuvant Chemotherapy}

After 2-4 courses of multiagent chemotherapy, we performed the second-look surgery. One patient with AT/RT diagnosed at 2 months of age received 4 courses of ICE chemotherapy, and 1 patient with CPC received 2 courses of ICE chemotherapy. The other 7 patients received 2 courses of the chemotherapy comprising vincristine, cyclophosphamide, etoposide, and cisplatin (Table 2). In 1 patient with a PNET, intratumoral hemorrhage was observed after 2 courses of chemotherapy. The mean interval between the initial surgery and the second-look surgery was 3 months (range 2.2-4.2 months). The tumor volume was reduced to varying degrees in 5 patients $(56 \%)$ after chemotherapy. The pathology of the tumor in these 5 patients was PNET in 2, AT/RT in 1, CPC in 1, and ETANTR in 1 . The average decrease of the largest diameter of the tumor after chemotherapy was 33\% (range 21\%-60\%). The tumor volume was unchanged in 2 patients. The pathology of the tumor in those patients was ependymoma in 1 and anaplastic ependymoma in 1 . The tumor volume increased after chemotherapy in 2 patients. The pathology of the tumor was ependymoma in 1 and glioblastoma in 1.

\section{Second-Look Surgery}

At the time of the second-look surgery, the vascularity of the tumor was considerably reduced and the tumor was more circumscribed in all cases. GTR was achieved in 8 patients $(89 \%)$ and NTR in $1(11 \%)$. The average blood loss was $150 \mathrm{ml}$ (range $10-450 \mathrm{ml}$ ) and $20 \%$ of the estimated blood volume (range 2\%-52\%). Three patients (33\%) required a blood transfusion in the perioperative period. There was no surgical mortality. One patient at 35 months of age had transient dysphasia postoperatively; no patient developed permanent neurological complications. Histopathological examination demonstrated fibrotic tissue circumscribing the tumor in 6 of the 9 cases (67\%) (Fig. 1). There was a trend that such fibrotic tissue circumscribing the tumor was demonstrated more in high-grade tumors $(6[86 \%]$ of 7$)$ than in low-grade tumors $(0[0 \%]$ of $2)(p=0.08)$. There were no correlations between fibrosis and the chemotherapy regimen or patient age. There were also no correlations between fibrosis and intraoperative blood loss of the estimated blood volume or the findings of preoperative MRI.

\section{Postoperative Outcome}

The mean follow-up period was 28 months (range 2-63 months). At the last follow-up, 2 patients (22\%) had died (due to tumor progression in 1 and sepsis in 1), and 4 patients $(44 \%)$ had no tumor recurrence.

\section{Illustrative Case Case 9}

A 14-month-old boy presented with nausea and nystagmus. MRI showed an $8 \times 5-\mathrm{cm}$ mass in the trigone of the left lateral ventricle (Fig. 2A). The patient underwent tumor resection; however, only a partial resection was achieved due to the significantly high tumor vascular- 
TABLE 1. Summary of treatments and outcomes for 9 children who underwent second-look surgery after chemotherapy

\begin{tabular}{|c|c|c|c|c|c|c|c|c|c|c|c|}
\hline $\begin{array}{l}\text { Case } \\
\text { No. }\end{array}$ & $\begin{array}{c}\text { Age at } \\
\text { Dx (mos), } \\
\text { Sex }\end{array}$ & $\begin{array}{l}\text { Tumor } \\
\text { Location }\end{array}$ & $\begin{array}{l}\text { Largest } \\
\text { Diameter } \\
\text { of Tumor } \\
\text { at Dx }(\mathrm{mm})\end{array}$ & Pathology & $\begin{array}{c}\text { No. of Chemo } \\
\text { Courses }\end{array}$ & $\begin{array}{l}\text { Change in } \\
\text { Tumor Vol } \\
\text { After Chemo }\end{array}$ & EOR & $\begin{array}{l}\text { EBL of } \\
\text { EBV }(\%)\end{array}$ & Transfusion & $\begin{array}{l}\text { Follow-Up } \\
\text { (mos) }\end{array}$ & Outcome \\
\hline 1 & $2, M$ & 3rd ventricle & 70 & AT/RT & 4 & Decrease & GTR & 39 & Yes & 2 & $\begin{array}{l}\text { Death (sep- } \\
\text { sis) }\end{array}$ \\
\hline 2 & $9, \mathrm{~F}$ & 3rd ventricle & 79 & PNET & 2 & Decrease & NTR & 12 & No & 22 & $\begin{array}{l}\text { Alive w/ dis- } \\
\text { ease }\end{array}$ \\
\hline 3 & $22, \mathrm{M}$ & Rt CPA & 43 & Ependymoma & 2 & No change & GTR & 47 & Yes & 15 & $\begin{array}{l}\text { Alive w/ dis- } \\
\text { ease }\end{array}$ \\
\hline 4 & $35, M$ & 4th ventricle & 50 & Ependymoma & 2 & Increase & GTR & 2.4 & No & 61 & $\begin{array}{l}\text { Alive w/ dis- } \\
\text { ease }\end{array}$ \\
\hline 5 & $16, F$ & Rt parietal & 98 & GBM & 2 & Increase & GTR & 8.4 & No & 63 & NED \\
\hline 6 & $3, \mathrm{~F}$ & 4th ventricle & 56 & ETANTR & 2 & Decrease & GTR & 1.8 & No & 25 & $\begin{array}{l}\text { Death (tumor } \\
\text { progres- } \\
\text { sion) }\end{array}$ \\
\hline 7 & $50, \mathrm{~F}$ & $\begin{array}{l}\text { Lt lateral } \\
\quad \text { ventricle }\end{array}$ & 130 & $\begin{array}{c}\text { Anaplastic } \\
\text { ependy- } \\
\text { moma }\end{array}$ & 2 & No change & GTR & 13 & No & 33 & NED \\
\hline 8 & $14, \mathrm{~F}$ & $\begin{array}{l}\text { Lt lateral } \\
\quad \text { ventricle }\end{array}$ & 30 & PNET & 2 & Decrease & GTR & 1.9 & No & 17 & NED \\
\hline 9 & $14, \mathrm{M}$ & $\begin{array}{l}\text { Lt lateral } \\
\text { ventricle }\end{array}$ & 82 & CPC & 2 & Decrease & GTR & 52 & Yes & 15 & NED \\
\hline
\end{tabular}

Chemo = chemotherapy; $\mathrm{CPA}$ = cerebellopontine angle; $\mathrm{Dx}$ = diagnosis; $\mathrm{EBL}$ = estimated blood loss; EBV = estimated blood volume; EOR = extent of resection; $\mathrm{GBM}=$ glioblastoma; NED = no evidence of disease.

ity. The histopathological diagnosis was a CPC. After 2 courses of ICE chemotherapy, the tumor size decreased to $6 \times 5 \mathrm{~cm}$ (Fig. 2B). The patient then underwent a definitive resection. In the second surgery, tumor vascularity decreased, the interface between the normal brain tissue and the tumor was clearer, and GTR was achieved (Fig. 2C). Histopathological examination demonstrated fibrotic tissue with hemosiderin circumscribing the tumor (Fig. 1). Postoperatively, the patient received 3 courses of ICE chemotherapy. At his last examination, 15 months after the second surgery, he had been stable without evidence of disease.

\section{Discussion}

The goal of the surgery in infants and young children with brain tumors is, in most cases, a GTR since a maximal resection has been proved to correlate with better survival for almost all major tumor types, including medulloblastomas, ependymomas, choroid plexus tumors, PNETs, AT/RTs, and high-grade gliomas. ${ }^{6}$ On the other hand, brain tumors in infants and young children are frequently large and highly vascular, and complete resection is often difficult due to the risks of neurological complications and excessive blood loss. Relatively small circulating blood volume in infants and young children lowers the

TABLE 2. Summary of neoadjuvant chemotherapy and intraoperative and histopathological findings of second-look surgery in 9 children

\begin{tabular}{|c|c|c|c|c|c|c|}
\hline $\begin{array}{l}\text { Case } \\
\text { No. }\end{array}$ & $\begin{array}{c}\text { Age at } \\
\text { Dx (mos) }\end{array}$ & Pathology & Type of Neoadjuvant Chemo & $\begin{array}{c}\text { No. of } \\
\text { Neoadjuvant } \\
\text { Chemo Courses }\end{array}$ & $\begin{array}{c}\text { Tumor Vascularity } \\
\text { at Second-Look } \\
\text { Surgery }\end{array}$ & $\begin{array}{c}\text { Fibrotic Tissue } \\
\text { Circumscribing } \\
\text { Tumor }\end{array}$ \\
\hline 1 & 2 & AT/RT & ICE & 4 & Decreased & Yes \\
\hline 2 & 9 & PNET & Vincristine, cyclophosphamide, etoposide, \& cisplatin & 2 & Decreased & No \\
\hline 3 & 22 & Ependymoma & Vincristine, cyclophosphamide, etoposide, \& cisplatin & 2 & Decreased & No \\
\hline 4 & 35 & Ependymoma & Vincristine, cyclophosphamide, etoposide, \& cisplatin & 2 & Decreased & No \\
\hline 5 & 16 & GBM & Vincristine, cyclophosphamide, etoposide, \& cisplatin & 2 & Decreased & Yes \\
\hline 6 & 3 & ETANTR & Vincristine, cyclophosphamide, etoposide, \& cisplatin & 2 & Decreased & Yes \\
\hline 7 & 50 & $\begin{array}{l}\text { Anaplastic } \\
\text { ependymoma }\end{array}$ & Vincristine, cyclophosphamide, etoposide, \& cisplatin & 2 & Decreased & Yes \\
\hline 8 & 14 & PNET & Vincristine, cyclophosphamide, etoposide, \& cisplatin & 2 & Decreased & Yes \\
\hline 9 & 14 & CPC & ICE & 2 & Decreased & Yes \\
\hline
\end{tabular}




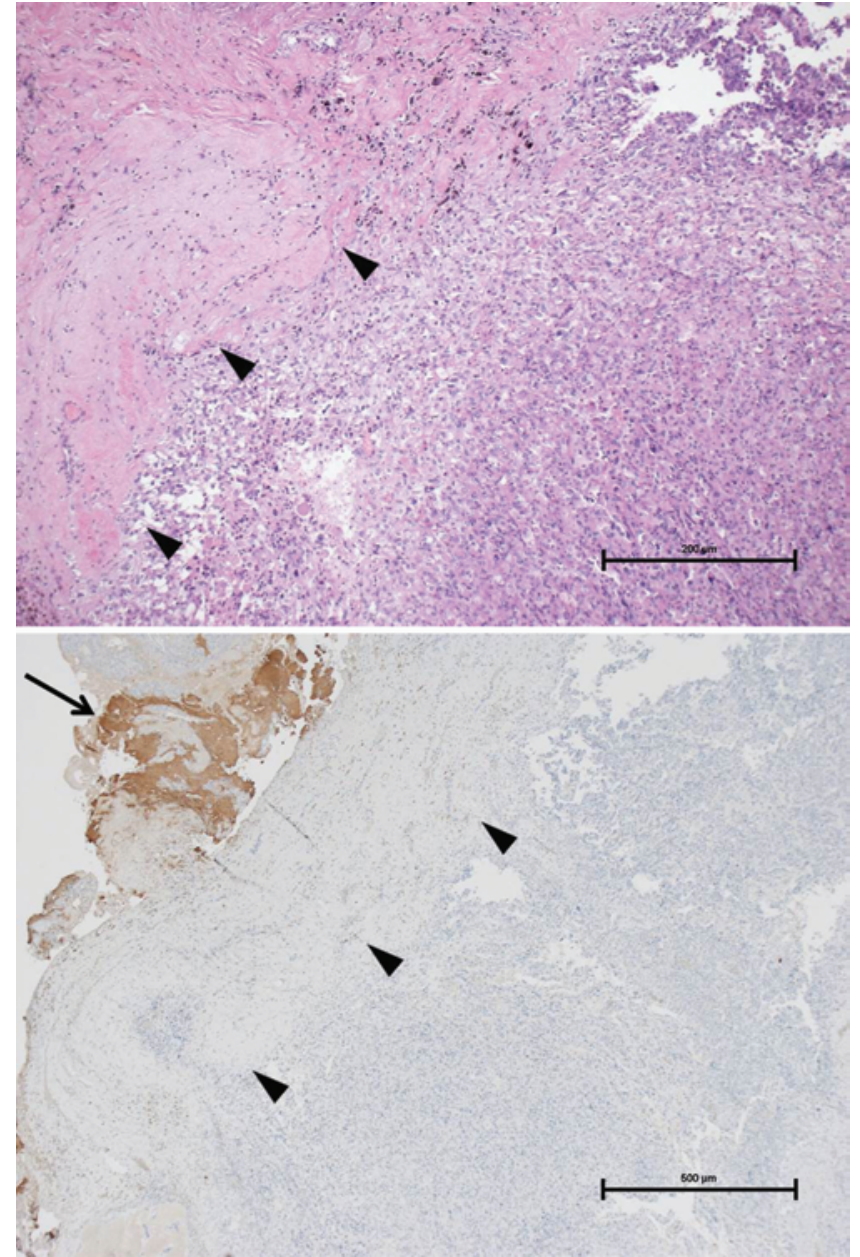

FIG. 1. Case 9. H \& E staining (upper) and GFAP staining (lower) of specimens obtained from the second-look surgery of a CPC, demonstrating fibrotic tissue (arrowheads) with hemosiderin circumscribing the tumor cells. Fibrotic tissue was located between tumor and normal glial tissue (arrow). Bar $=200 \mu \mathrm{m}$ in upper; bar $=500 \mu \mathrm{m}$ in lower. Figure is available in color online only. threshold of tolerance for intraoperative blood loss. In our series, neoadjuvant chemotherapy decreased the tumor vascularity and facilitated maximal resection, as previous studies have demonstrated.,5,9 The tumor resection was not hampered by hemorrhage from the tumor in all cases, and GTR was achieved in 89\% (8 of 9 patients). The average estimated blood loss in our series was $20 \%$ of the estimated blood volume, which is comparable to that in previous studies with neoadjuvant chemotherapy $(15 \%-$ $19 \%){ }^{1,9}$ Three patients (33\%) required a blood transfusion in our series, and there were no complications associated with the transfusion. Lafay-Cousin et al. reported the efficacy of neoadjuvant chemotherapy for reduction in tumor vascularity with CPCs. ${ }^{5}$ Intraoperative blood loss was also significantly reduced in that series. The authors demonstrated that perivascular collagen within the fibrovascular core of the tumor papillae increased after ICE chemotherapy, which they suspect contributed to a decrease in tumor vascularity. ${ }^{5}$

The other advantage of neoadjuvant chemotherapy for resection was reduction in tumor volume. In our series, the tumor volume decreased in 5 patients $(56 \%)$ due to chemotherapy. The pathologies harbored by these 5 patients were PNET in 2, AT/RT in 1, CPC in 1, and ETANTR in 1. Van Poppel et al. also reported that $69 \%$ (9 of 13) demonstrated a decrease in tumor volume by neoadjuvant chemotherapy for infantile tumors. ${ }^{9}$ In terms of histopathology, 3 PNETs, 2 AT/RTs, 1 CPC, 2 ependymomas, and 1 high-grade glioma responded to chemotherapy. ${ }^{9}$ Lafay-Cousin et al. reported that 5 of 10 patients with CPC showed response to neoadjuvant ICE chemotherapy and tumor volume decreased, which facilitated further resection. ${ }^{5}$ According to these results, PNET, AT/RT, and CPC tend to respond to chemotherapy. In all PNET and AT/RT cases and in more than half of the CPC cases, tumor size was reduced by chemotherapy.

Neoadjuvant chemotherapy also made tumors more circumscribed and defined, which makes it easier to dissect them from surrounding brain tissues and potentially decrease morbidity. ${ }^{3,8,9}$ We demonstrated the fibrotic tissue circumscribing the tumor on histopathological examination of the specimen after neoadjuvant chemotherapy in
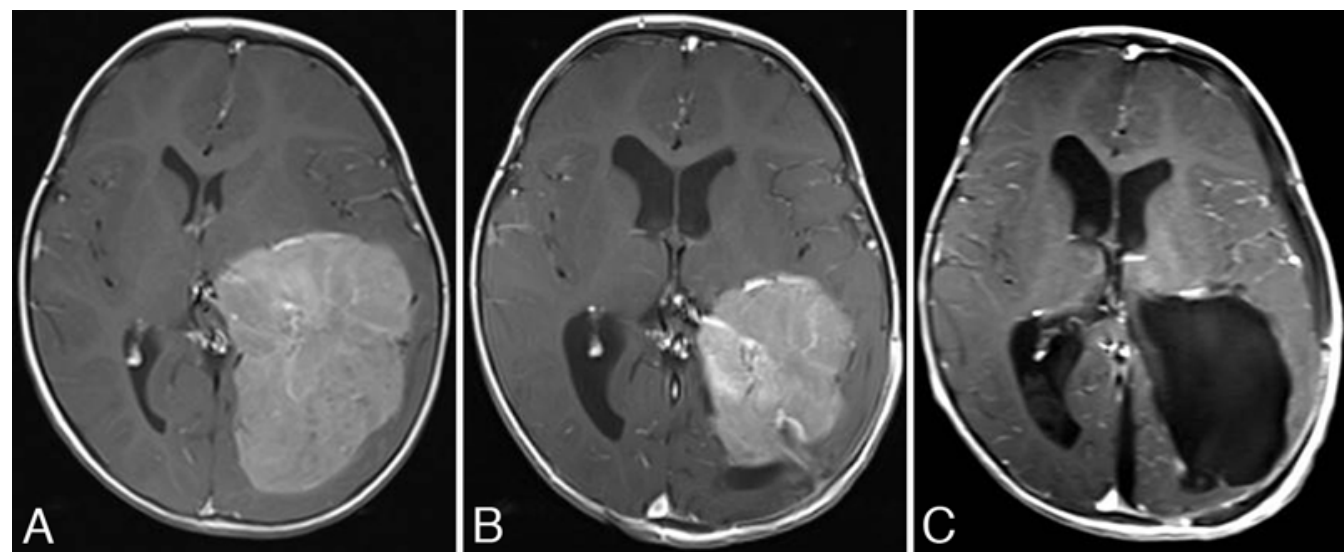

FIG. 2. Case 9. Axial T1-weighted MR images with contrast. A: Image obtained at diagnosis, demonstrating the enhanced mass in the trigone of the left lateral ventricle. B: Image showing a decrease in tumor size after chemotherapy. C: Postoperative image showing GTR of an intraventricular tumor. 
6 cases (67\%), as shown in Fig. 1. This fibrotic tissue circumscribing the tumor functioned as an interface between the tumor and surrounding normal brain tissues, and was considered to make the boundary clearer and the tumor dissection easier. This was the first histopathological demonstration of the circumscribed tumor after neoadjuvant chemotherapy, although subjective impression had been addressed about the tumor being more circumscribed after chemotherapy. ${ }^{3,8,9}$ In our series and previous studies, ependymoma showed slight or no tumor shrinkage, or increase in tumor size after neoadjuvant chemotherapy. ${ }^{9}$ Nevertheless, neoadjuvant chemotherapy significantly facilitated safe and maximal resection of ependymoma by making it more circumscribed. It was considered useful, especially in ependymomas of the fourth ventricle or the cerebellopontine angle. In these locations, it is very important to dissect the tumor safely from the floor of the fourth ventricle or the cranial nerves to achieve safe and maximal resection. Neoadjuvant chemotherapy facilitated the dissection, as a previous study has addressed. ${ }^{3}$ In our series, one patient with cerebellopontine angle ependymoma underwent GTR without any complications, and another patient with a fourth ventricle ependymoma underwent GTR with transient dysphasia.

\section{Conclusions}

Neoadjuvant chemotherapy for brain tumors in infants and young children was effective in reduction of tumor vascularity and clarification of the tumor-brain interface, which significantly facilitated maximal tumor resection.

\section{References}

1. Duffner PK, Cohen ME: Long-term consequences of CNS treatment for childhood cancer, Part II: Clinical consequences. Pediatr Neurol 7:237-242, 1991

2. Duffner PK, Horowitz ME, Krischer JP, Burger PC, Cohen ME, Sanford RA, et al: The treatment of malignant brain tumors in infants and very young children: an update of the
Pediatric Oncology Group experience. Neuro Oncol 1:152161,1999

3. Foreman NK, Love S, Gill SS, Coakham HB: Second-look surgery for incompletely resected fourth ventricle ependymomas: technical case report. Neurosurgery 40:856-860, 1997

4. Heideman RL, Kuttesch J Jr, Gajjar AJ, Walter AW, Jenkins JJ, Li Y, et al: Supratentorial malignant gliomas in childhood: a single institution perspective. Cancer 80:497-504, 1997

5. Lafay-Cousin L, Mabbott DJ, Halliday W, Taylor MD, Tabori U, Kamaly-Asl ID, et al: Use of ifosfamide, carboplatin, and etoposide chemotherapy in choroid plexus carcinoma. J Neurosurg Pediatr 5:615-621, 2010

6. Lafay-Cousin L, Strother D: Current treatment approaches for infants with malignant central nervous system tumors. Oncologist 14:433-444, 2009

7. Massimino M, Solero CL, Garrè ML, Biassoni V, Cama A, Genitori L, et al: Second-look surgery for ependymoma: the Italian experience. J Neurosurg Pediatr 8:246-250, 2011

8. Sanford RA, Horowitz ME, Kun LE, Jenkins JJ III, Simmons JCH, Kovnar EH: Preoperative chemotherapy to facilitate the total resection of pediatric brain tumors. Concepts Pediatr Neurosurg 9:139-152, 1989

9. Van Poppel M, Klimo P Jr, Dewire M, Sanford RA, Boop F, Broniscer A, et al: Resection of infantile brain tumors after neoadjuvant chemotherapy: the St. Jude experience. J Neurosurg Pediatr 8:251-256, 2011

\section{Author Contributions}

Conception and design: Ogiwara, Iwama, Morota. Acquisition of data: all authors. Analysis and interpretation of data: all authors. Drafting the article: Ogiwara, Iwama. Critically revising the article: Ogiwara, Kiyotani, Terashima, Matsuoka. Reviewed submitted version of manuscript: Ogiwara, Iwafuchi, Morota. Approved the final version of the manuscript on behalf of all authors: Ogiwara. Statistical analysis: Ogiwara.

\section{Correspondence}

Hideki Ogiwara, Division of Neurosurgery, National Center for Child Health and Development, Okura 2-10-1, Setagaya-ku, Tokyo 157-8535, Japan. email: hideki_o@d5.dion.ne.jp. 